\title{
Forrest-Wilson, Anne, dir. Sur les traces de Champlain. Un voyage extraordinaire en
} 24 tableaux. Sudbury : Prise de parole, 2015. Sudbury : Prise de parole, 2015. 298 p.

Si les maisons d'édition sont sans doute peu enclines à considérer des manuscrits rédigés à la va-vite, Sur les traces de Champlain. Un voyage extraordinaire en 24 tableaux montre que la rapidité peut pourtant être un atout. Les nouvelles contenues dans l'ouvrage, chacune d'un auteur différent, ont, en effet, été écrites en vingt-quatre heures, et la lecture, c'est le moins qu'on puisse dire, en vaut la peine.

A l'automne 2015, vingt-quatre auteurs (deux Acadiens, six Français, dix Ontariens, deux Premières Nations et quatre Québécois) ont pris le train de Halifax en Nouvelle-Ecosse à Toronto dans l'Ontario avec pour mission de rédiger chacun un texte complet durant le trajet. Le sujet est vaste : la vie et les aventures de Samuel Champlain au Canada depuis l'hiver meurtrier passé sur l'Ile Sainte-Croix en Acadie jusqu'aux explorations dans l'Ontario, les alliances avec les populations autochtones, les conflits armés aussi, et la mort du voyageur. Les peuples wendats, montagnais, micmacs, algonquins et d'autres encore sont au rendez-vous de l'histoire. Autour de Champlain, les lecteurs rencontreront, dans l'une ou l'autre nouvelle, Nicolas Vignau et Thomas Godefroy, compagnons d'explorations; Andicha, jeune femme wendat qui n'a pas su séduire le récalcitrant Champlain mais qui a trouvé un amoureux en son valet ; Eslayne Boullé, femme de Champlain, qui ne se plaisait pas beaucoup en Nouvelle-France ; Etienne Brûlé, «truchement » acquis à la vie parmi les autochtones ; Gaston Lheureux, triste valet de l'explorateur ; Mathurin, le colon espiègle ; sans oublier quelques monstres aquatiques tels que la Gougou dont le passage se remarque par les algues qu'elle dépose. Tout un réseau de relations est ainsi reconstruit (et imaginé) sous la houlette d'Anne ForrestWilson, tisseuse du fil d'histoires qui assure au livre sa chronologie et sa diversité. Les talents regroupés sont variés et la lecture en est donc autant remplie de surprises et de nouvelles perspectives.

Dans l'épilogue, Olivier Salon écrit qu'en si peu de temps, les auteurs du livre ont fait la connaissance de "Champlain l'aventurier, Champlain l'explorateur, Champlain l'intrépide, Champlain le négociateur auprès de la Cour et du Roi, Champlain le mari, Champlain le médiateur, Champlain le pétunier (liste non close) ». Cela a eu lieu à Moncton, «le mardi soir, de façon encore assez nébuleuse, lorsque les vingt-quatre 
écrivains ont été pour la première fois réunis. Là, les thèmes étaient attribués, les échanges entre écrivains permettaient d'explorer le tuilage des chapitres et le voile se dissipait, tout autant qu'on pouvait alors commencer à envisager la possibilité de ce qui n'était jusque-là que potentialité ».

Sur les traces de Champlain. Un voyage extraordinaire en 24 tableaux nous propose une plaisante ribambelle d'épisodes de plumes différentes et est le produit d'une écriture à contraintes soigneusement épelées par la coordinatrice du périple. Le récit suit des recettes précises pour mieux dégager un fumet de liberté inventive dans le déroulement des chapitres. Pour nous mettre en appétit, voici quelques titres évocateurs : le titre du chapitre le plus long est « Les cheveux de la Gougou et autres curiosités répertoriées dans la caisse mystérieuse expédiée à Paris au bon Vespasien Robin, botaniste du roi, par le sieur de Champlain en 1637, par-delà sa mort », alors que trois chapitres ont un titre d'un seul mot («Mistenapeo » qui reprend le nom d'un autochtone montagnais qui passa deux ans en France ; «Petitous », jeune femme abénaki, première à épouser un Français ; «Kanienkehaka», groupe appartenant au peuple iroquois); le spirituel («L'esprit du lac ») s'associe au charnel « Moi, le grand masturbateur devant l'Eternel »; les premières expériences en nouvelle terre («Premières vendanges») laissent place à la fin d'une aventure («Dernier voyage en Ontario »). Sur les traces de Champlain met en scène une vie mouvementée qui a bouleversé à jamais d'immenses terres et la vie de leurs habitants.

Comme, par exemple, J'écris Champlain (Salon du livre de Toronto, 2015) réalisé par des enfants participant à des ateliers d'écriture, dont le sujet est aussi Champlain et ses explorations, Sur les traces de Champlain. Un voyage extraordinaire en 24 tableaux s'inscrit dans le cadre des événements culturels des «400 ans de présence française en Ontario » qui ont marqué 2015. Peut-on alors qualifier cette compilation de vingt-quatre récits d'œuvre de circonstances? Sans doute, mais c'est avant tout une œuvre réussie, inhabituelle et passionnante. Tout y finit par une chanson, un « Track 24 » qui conclut les vingt-quatre chapitres des vingt-quatre intrépides auteurs en train.

Emilienne Rue 